\title{
Preoperative leukocytosis and the resection severity index are independent risk factors for survival in patients with intrahepatic cholangiocarcinoma
}

\author{
Oliver Beetz ${ }^{1}$ (D) C Clara A. Weigle ${ }^{1} \cdot$ Sebastian Cammann ${ }^{1} \cdot$ Florian W. R. Vondran $^{1} \cdot$ Kai Timrott $^{1} \cdot$ Ulf Kulik $^{1} \cdot$ \\ Hüseyin Bektas ${ }^{2} \cdot$ Jürgen Klempnauer ${ }^{1} \cdot$ Moritz Kleine $^{1} \cdot$ Felix Oldhafer $^{1}$
}

Received: 4 April 2020 / Accepted: 9 August 2020 / Published online: 19 August 2020

(C) The Author(s) 2020

\begin{abstract}
Purpose The incidence of intrahepatic cholangiocarcinoma is increasing worldwide. Despite advances in surgical and nonsurgical treatment, reported outcomes are still poor and surgical resection remains to be the only chance for long-term survival of affected patients. The identification and validation of prognostic factors and scores, such as the recently introduced resection severity index, for postoperative morbidity and mortality are essential to facilitate optimal therapeutic regimens.

Methods This is a retrospective analysis of 269 patients undergoing resection of histologically confirmed intrahepatic cholangiocarcinoma between February 1996 and September 2018 at a tertiary referral center for hepatobiliary surgery. Regression analyses were performed to evaluate potential prognostic factors, including the resection severity index.

Results Median postoperative follow-up time was 22.93 (0.10-234.39) months. Severe postoperative complications ( $\geq$ ClavienDindo grade III) were observed in 94 (34.9\%) patients. The body mass index ( $p=0.035)$, the resection severity index (ASAT in $\mathrm{U} / 1$ divided by Quick in $\%$ multiplied by the extent of liver resection graded in points; $p=0.006$ ), additional hilar bile duct resection $(p=0.005)$, and number of packed red blood cells transfused during operation $(p=0.036)$ were independent risk factors for the onset of severe postoperative complications. Median Kaplan-Meier survival after resection was 27.63 months. Preoperative leukocytosis $(p=0.003)$, the resection severity index $(p=0.005)$, multivisceral resection $(p=0.001)$, and T stage $\geq 3(p=0.013)$ were identified as independent risk factors for survival.

Conclusion Preoperative leukocytosis and the resection severity index are useful variables for preoperative risk stratification since they were identified as significant predictors for postoperative morbidity and mortality, respectively.
\end{abstract}

Keywords Intrahepatic cholangiocarcinoma $\cdot$ Resection severity index $\cdot$ Extended surgery $\cdot$ Leukocytosis

\section{Introduction}

Intrahepatic cholangiocarcinoma (ICC) is a malignant disease of the intrahepatic bile ducts. Although only accounting for 10 to $20 \%$ of primary hepatic malignancies, incidence and mortality rates are continuously increasing world-wide [1]. Recent

Moritz Kleine and Felix Oldhafer contributed equally to this work.

Oliver Beetz

Beetz.Oliver@mh-hannover.de

1 Department of General, Visceral and Transplant Surgery, Hannover Medical School, Carl-Neuberg-Strasse 1, 30625 Hannover, Germany

2 Department of General, Visceral and Oncological Surgery, Hospital Group Gesundheit Nord, Bremen, Germany epidemiological data from Germany has shown incidence and mortality rates of 1 to 2 cases per 100,000 [2].

Despite the introduction of more effective chemotherapy regimens in the past, the prognosis of a majority of patients with unresectable ICC is dismal, with reported median survival times of approximately 12 months [3, 4]. Therefore, local ablative procedures, such as radiofrequency ablation, transarterial chemoembolization, or selective internal radiation therapy and even liver transplantation are increasingly under (re) evaluation [5-9].

Complete surgical resection is still regarded as only chance for long-term survival of affected patients; however, the reported survival after resection remains poor with 5-year survival rates ranging between 20 and $35 \%$ [10].

In light of the above-mentioned epidemiologic trends and developing therapeutic alternatives, identification of 
prognostic factors for morbidity and mortality after surgical resection of ICC, especially in cases of advanced disease, is essential to determine optimal treatment strategies.

Recently, we have introduced the resection severity index (RSI) reflecting the degree of liver function and liver cell damage, as well as the extent of hepatic resection, as an independent risk factor for survival in patients with hepatocellular carcinoma and colorectal liver metastases undergoing surgery $[11,12]$.

The aim of this study was to evaluate the influence of the RSI among other factors on the postoperative morbidity and mortality of patients with ICC undergoing hepatic resection.

\section{Material and methods}

\section{Study design and patient cohort}

This is a retrospective analysis of 269 patients with ICC undergoing surgery between February 1996 and September 2018 at the Department of General, Visceral and Transplant Surgery, Hannover Medical School, Germany.

\section{Inclusion and exclusion criteria}

Included were all patients with intraoperatively and histologically confirmed ICC receiving hepatic resection in curative intent older than 18 years of age. Patients with hilar cholangiocarcinoma (defined by the localization of the main tumor mass) were explicitly excluded from our study

Patients undergoing surgery for tumor recurrence were excluded from the study. Four patients were lost to follow-up immediately after discharge and were therefore excluded from further survival analysis. No further exclusion criteria were defined.

\section{Definition of variables}

Preoperative leukocytosis was defined as a leukocyte concentration of more than 11,000 per $\mu \mathrm{l}$ [13]. Preoperative anemia was defined as hemoglobin concentrations lower than $11.5 \mathrm{~g} /$ $\mathrm{dl}$ in female patients and lower than $13.5 \mathrm{~g} / \mathrm{dl}$ in male patients, as recently suggested [14].

The resection severity index (RSI) was initially developed as an interaction variable in a multivariable regression model in patients with hepatocellular carcinoma undergoing surgical resection and is defined as ASAT in U/l divided by Quick in $\%$ multiplied by the extent of liver resection graded in points (Table 1) [11]. The theoretical background of this mathematical formula is an attempt to quantify the degree of liver damage (ASAT), functional liver capacity (Quick), and the expected or actual extent of liver resection (graded in points) and thus the (future) functional liver remnant. For regression analysis, the RSI was used as continuous variable, whereas for Log-rank analysis, three tertiles were computed (low, intermediate, and high).

Major hepatectomies were defined as resections of three or more liver segments, whereas extended hepatectomies were defined as resection of five or more segments, based on the Brisbane classification [15]. Vascular resections were defined as additional partial resection of the vena cava inferior or the portal vein. Multivisceral resections were defined as additional resections of extrahepatic tissue (excluding hilar bile ducts and large vessels) due to suspected infiltration.

Postoperative complications were graded according to the Clavien-Dindo classification ranging from grade 0 (no complications), grade I (minor deviations), grade II (requiring pharmacologic treatment), grade III (requiring interventions), grade IV (life-threatening) to grade V (death) [16]. Severe complications were defined as complications $\geq$ grade III.

Additionally, typical posthepatectomy complications (hemorrhage, liver failure, or biliary leakage) requiring invasive treatment and surgical revision, respectively, (classified as Grade $\mathrm{C}$ complications by the International Study Group of Liver Surgery (ISGLS)) were evaluated [17].

For classification of ICC, the AJCC/UICC $8^{\text {th }}$ edition was applied [18]. Of note, to avoid retrospective misclassification, patients were only classified if pathological parameters available allowed for distinct allocation.

Liver specimens were further reviewed for steatosis (graded into mild (5-33\%), moderate (34-66\%), or severe (> $66 \%)$ ), fibrosis, and cirrhosis as well as for cholestasis and cholangitis [19].

Three approximately equally long time periods were defined to analyze if not further specifiable adjustments or improvements in perioperative care and surgical strategies had impact on postoperative survival.

Follow-up time was defined as time between date of surgery and date of last contact or death, respectively. Survival times are reported as the Kaplan-Meier median estimates.

\section{Study endpoints}

Primary endpoints were the incidence of severe postoperative complications and overall survival after resection of ICC.

\section{Statistical analysis}

Mean and median values were compared with Student's $t$ test in case of normal distribution or the Mann-Whitney $U$ test. The distribution of categorical variables between groups was compared with the chi-squared and the Fisher's exact test.

Risk factors for the incidence of severe postoperative complications were analyzed with univariable binary logistic regression analysis. Independent risk factors were identified by purposeful selection of variables with a rate of missing values 
Table 1 Descriptive statistics of the study cohort undergoing resection for intrahepatic cholangiocarcinoma

\begin{tabular}{|c|c|c|c|c|c|}
\hline \multicolumn{3}{|l|}{ Variables } & $n_{\mathrm{abs}}\left(n_{\%}\right)$ & Mean; median (range) & $\begin{array}{l}\text { Missing } \\
\text { values } n(\%)\end{array}$ \\
\hline \multirow[t]{4}{*}{ Biometrics } & \multirow{2}{*}{\multicolumn{2}{|c|}{$\begin{array}{l}\text { Male gender } \\
\text { Female gender }\end{array}$}} & $134(49.8)$ & & \multirow[t]{2}{*}{$0(0)$} \\
\hline & & & $135(50.2)$ & & \\
\hline & \multicolumn{2}{|l|}{ Age (in years) } & & $61.11 ; 62(24-83)$ & $0(0)$ \\
\hline & \multicolumn{2}{|l|}{ Body mass index (in $\mathrm{kg} / \mathrm{m}^{2}$ ) } & & $25.74 ; 25.20(16.36-55.36)$ & $5(1.9)$ \\
\hline \multirow{10}{*}{$\begin{array}{l}\text { Preoperative } \\
\text { laboratory results }\end{array}$} & \multicolumn{2}{|l|}{ Hemoglobin (in $\mathrm{g} / \mathrm{dl}$ ) } & & $13.14 ; 13.30(8.2-17.2)$ & $1(0.4)$ \\
\hline & \multicolumn{2}{|l|}{ Anemia } & $78(29.0)$ & & $1(0.4)$ \\
\hline & \multicolumn{2}{|l|}{ Leukocytes (in $10^{3} / \mu \mathrm{l}$ ) } & & $8.32 ; 7.7(1.7-24.1)$ & $1(0.4)$ \\
\hline & \multicolumn{2}{|l|}{ Leukocytosis } & $39(14.5)$ & & $1(0.4)$ \\
\hline & \multicolumn{2}{|l|}{ Platelets (in $10^{3} / \mu \mathrm{l}$ ) } & & $281 ; 254(69-902)$ & $2(0.7)$ \\
\hline & \multicolumn{2}{|l|}{ Quick (in \%) } & & $97.79 ; 99.5(46-147)$ & $3(1.1)$ \\
\hline & \multicolumn{2}{|l|}{ ASAT (in U/l) } & & $38.8 ; 30.5(4-304)$ & $7(2.6)$ \\
\hline & \multicolumn{2}{|l|}{ ALAT (in U/l) } & & $41.0 ; 26(5-543)$ & $49(18.2)$ \\
\hline & \multicolumn{2}{|l|}{ Bilirubin (in $\mu \mathrm{mol} / \mathrm{l}$ ) } & & $20.6 ; 9(3-445)$ & $10(3.7)$ \\
\hline & \multicolumn{2}{|l|}{ Creatinine (in $\mu \mathrm{mol} / \mathrm{l}$ ) } & & $69.27 ; 66(39-165)$ & $6(2.2)$ \\
\hline \multirow[t]{12}{*}{ Surgical details } & \multicolumn{2}{|l|}{$\begin{array}{l}\text { Major hepatectomy } \\
\text { Extended hepatectomy }\end{array}$} & $\begin{array}{l}224(83.3) \\
95(35.3)\end{array}$ & & $0(0)$ \\
\hline & \multirow[t]{5}{*}{ Resection points } & $\begin{array}{l}1 \text { (atypical) } \\
2 \text { (segmental) }\end{array}$ & $\begin{array}{l}17(6.3) \\
31(11.5)\end{array}$ & & $0(0)$ \\
\hline & & 3 (left hemihepatectomy) & $85(31.6)$ & & \\
\hline & & 4 (right hemihepatectomy) & $41(15.2)$ & & \\
\hline & & 5 (extended left) & $31(11.5)$ & & \\
\hline & & 6 (extended right) & $64(23.8)$ & & \\
\hline & \multicolumn{2}{|c|}{ RSI (ASAT $\div$ Quick $\times$ Resection points) } & & $1.69 ; 1.04(0.13-33.78)$ & $9(3.3)$ \\
\hline & \multicolumn{2}{|l|}{$\begin{array}{l}\text { Hilar bile duct resection } \\
\text { Vascular resection }\end{array}$} & $\begin{array}{l}51(19.0) \\
10(3.7)\end{array}$ & & $0(0)$ \\
\hline & \multicolumn{2}{|l|}{ Multivisceral resection } & $11(4.1)$ & & \\
\hline & \multicolumn{2}{|l|}{ Operation time (in min) } & & 203.77; 190 (67-780) & $4(1.5)$ \\
\hline & $\begin{array}{l}\text { Pringle maneuver } \\
\text { Pringle maneuver (in min) }\end{array}$ & & $208(77.3)$ & $23.19 ; 22(0-110)$ & $26(9.7)$ \\
\hline & $\begin{array}{l}\text { Intraoperative PRBC } \\
\text { Intraoperative PRBC (n) }\end{array}$ & & $130(48.3)$ & $2.03 ; 0(0-17)$ & $6(2.2)$ \\
\hline Postoperative & $\mathrm{T}$ staging & Tumor size (in cm) & & $7.55 ; 7.0(0.5-21.0)$ & $2(0.7)$ \\
\hline pathological results & & Vascular invasion & $59(21.9)$ & & $109(40.5)$ \\
\hline & & Multifocal & $98(36.4)$ & & $0(0)$ \\
\hline & & $\begin{array}{l}1 \mathrm{a} \\
1 \mathrm{~b}\end{array}$ & $\begin{array}{l}22(8.2) \\
45(16.7)\end{array}$ & & $44(16.4)$ \\
\hline & & 2 & $99(36.8)$ & & \\
\hline & & 3 & $16(5.9)$ & & \\
\hline & & 4 & $43(16.0)$ & & \\
\hline & & $\geq 3$ & $59(21.9)$ & & $1(0.4)$ \\
\hline & Lymph node status & Lymphadenectomy & $172(63.9)$ & & $0(0)$ \\
\hline & & Lymph nodes (n total) & & $4.98 ; 3(1-23)$ & $98(36.4)$ \\
\hline & & Lymph nodes (n positive) & & $1.13 ; 0(0-11)$ & $98(36.4)$ \\
\hline & & N 1 stage & $76(28.3)$ & & $96(35.7)$ \\
\hline & M 1 stage & & $7(2.6)$ & & $0(0.0)$ \\
\hline & Grading & $\begin{array}{l}1 \\
1-2\end{array}$ & $\begin{array}{l}3(1.1) \\
2(0.7)\end{array}$ & & $5(1.9)$ \\
\hline & & 2 & $183(68.0)$ & & \\
\hline & & $2-3$ & $12(4.5)$ & & \\
\hline & & 3 & $64(23.8)$ & & \\
\hline
\end{tabular}


Table 1 (continued)

\begin{tabular}{llll}
\hline Variables & & $n_{\text {abs }}\left(n_{\%}\right)$ & Mean; median (range) \\
& & $223(82.9)$ & $3(13.8)$ \\
values $n(\%)$
\end{tabular}

Clinical, surgical, and histopathological data of the 269 patients undergoing surgery for intrahepatic cholangiocarcinoma

ASAT aspartate aminotransferase, $A L A T$ alanine aminotransferase, $R S I$ resection severity index, $P R B C$ packed red blood cells, AJCC American Joint Committee on Cancer, UICC Union for International Cancer Control

of $<10 \%$ and $p$ values in univariable logistic regression of $<$ 0.300 and consecutive stepwise forward selection.

The identification of risk factors for postoperative survival was achieved by univariable and multivariable Cox regression analysis, as described above. Kaplan-Meier analyses including log-rank tests were performed where appropriate.

Statistical significance was set at a $p$ value of $<0.050$ and is shown bold (tables) or marked with an asterisk (figures).

The collected data was implemented and analyzed using SPSS statistical software (version 26; SPSS Inc.; IBM Corporation, Armonk, NY, USA). Figures were created with GraphPad Prism (version 8.3.0 for Windows, GraphPad Software, La Jolla, CA, USA).

\section{Results}

\section{Preoperative course}

The median age of patients undergoing hepatic resection for ICC was 62 (24-83) years. An equal gender distribution was observed among the included patients.

Upon admission, standardized preoperative laboratory testing revealed anemia in 78 (29.0\%) patients, and leukocytosis in $39(14.5 \%)$ patients. Whereas anemia resulted in a nonsignificant lower median survival (25.23 versus 30.33 months; $p=0.052$ ), preoperative leukocytosis was associated with a significantly inferior survival after hepatic resection (15.71 versus 31.87 months; $p=0.001$; Fig. 1a). Of note, median serum bilirubin concentration was not significantly elevated in case of preoperative leukocytosis (10 versus 9 $\mu \mathrm{mol} / 1 ; p=0.814)$.

Further information on biometrical and laboratory data is provided in Table 1.

\section{Hepatic resection}

Atypical or segmental resections were carried out in 48 $(17.8 \%)$ patients. Left or right hemihepatectomy was performed in 126 (46.8\%) patients. Ninety-five (35.3\%) patients received extended left or right hemihepatectomy. None of the operations was performed minimally invasive.

The RSI was calculated for each patient as described above, resulting in a median value of 1.04 (0.13-33.78), and three tertiles: low $(\leq 0.71 ; 87$ patients), intermediate $(0.72-$ $1.63 ; 86$ patients), and high ( $\geq 1.64 ; 87$ patients). Further analyses revealed a significant influence of RSI classification on postoperative survival $(39.62>27.93>22.28$ months; general trend: $p=0.040$; low versus high $p=0.009$; low versus intermediate: $p=0.313$; intermediate versus high: $p=$ 0.164 ; Fig. 1b).

Major hepatectomies were performed in 224 (83.3\%) patients. Of these, $95(42.4 \%)$ cases were graded as extended resections. 

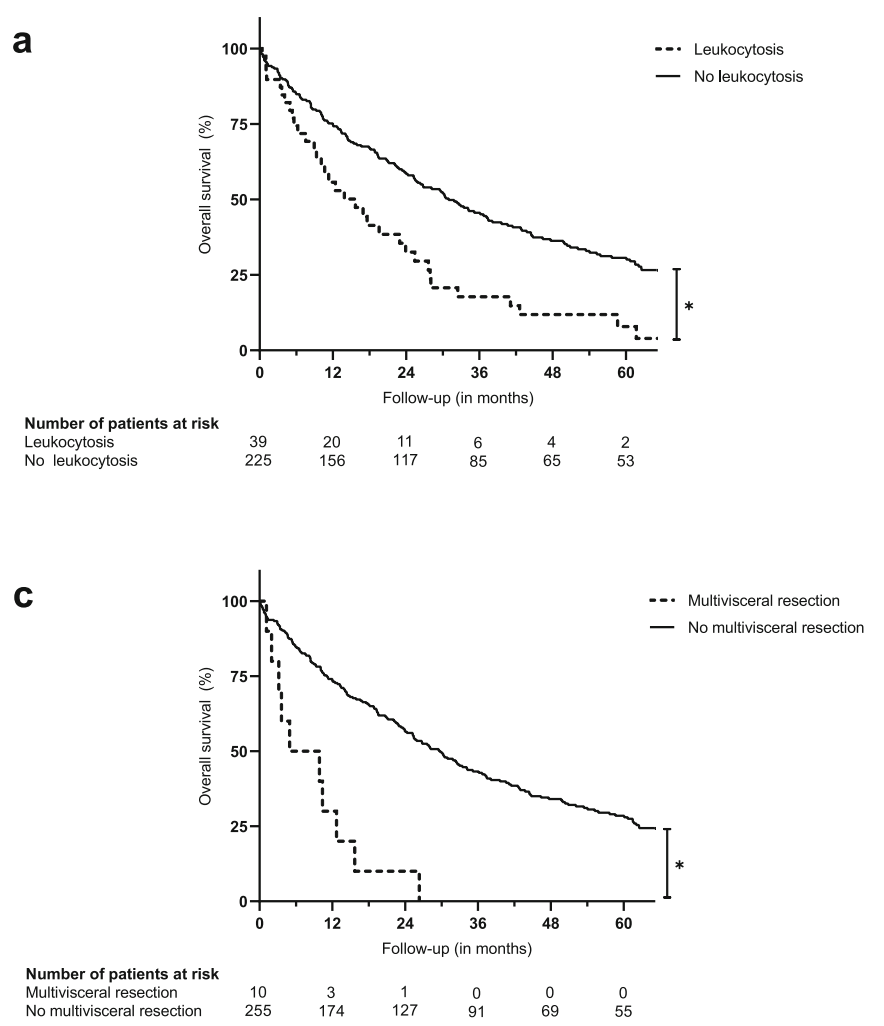

Fig. 1 Kaplan-Meier survival after resection of intrahepatic cholangiocarcinoma for variables identified as independent significant risk factors. a Preoperative leukocytosis $(* p=0.001)$. b Low,

Additional hilar bile duct resection was carried out in 51 $(19.0 \%)$ patients and was associated with significantly inferior postoperative survival (14.88 versus 28.16 months; $p=0.012$ ).

Ten $(3.7 \%)$ patients underwent additional vascular resection of the inferior vena cava or portal vein and showed significantly inferior postoperative survival (5.62 versus 29.50 months; $p=0.027$ ).

Multivisceral resections, including (partial) resections of the diaphragm, peritoneum, pericardium, stomach, greater omentum, small intestine, pancreas, and kidney were performed in $11(4.1 \%)$ patients due to intraoperatively suspected continuous or distant infiltration and were associated with significantly inferior survival (4.96 versus 29.70 months; $p<$ 0.001; Fig. 1c).

A total of 208 (77.3\%) patients underwent the Pringle maneuver during hepatic resection. Clamping was performed intermittent: Hepatic perfusion was interrupted for a maximum of 10 min before unclamping the hepatoduodenal ligament for a minimum of $5 \mathrm{~min}$. The values reported in Table 1 refer to the total amount of interrupted hepatic blood for each patient.

Intraoperative blood transfusion was performed in 130 (48.3\%) patients with a median of 3 (1-17) units of packed red blood cells (PRBC) and was associated with significantly inferior postoperative survival (22.93 versus 31.87 months; $p=0.011$ ).
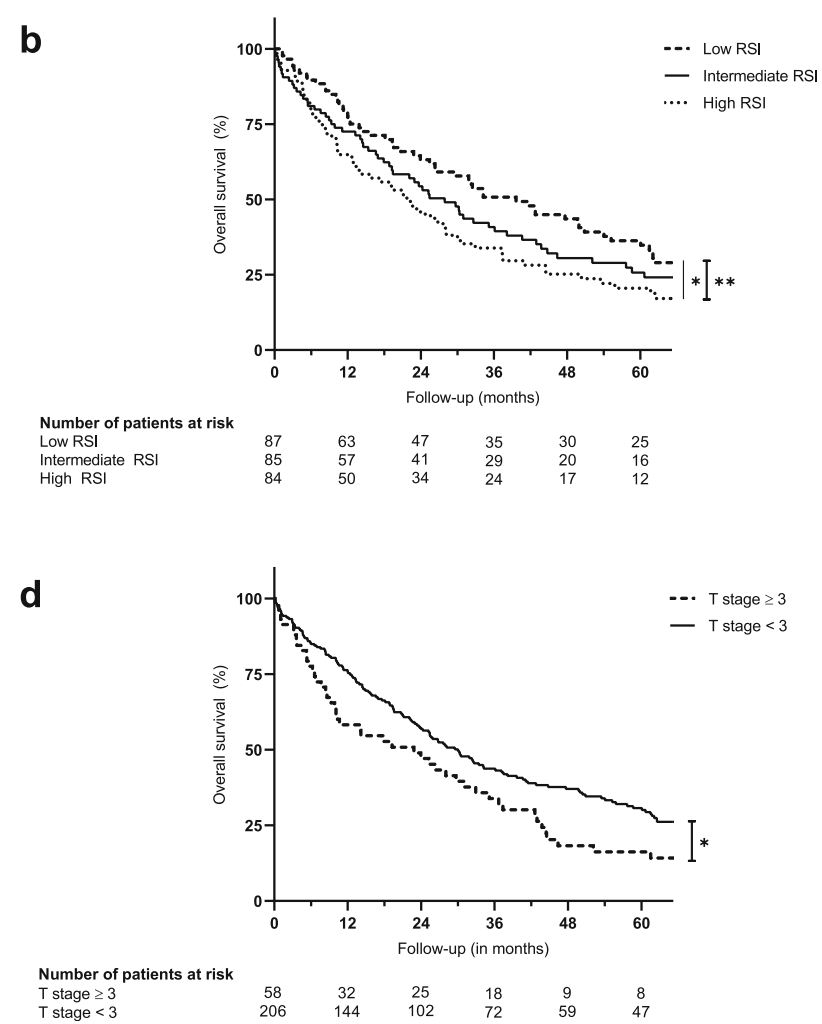

intermediate, or high RSI (general trend $* p=0.040$; low versus high $* * p=0.009)$. c Multivisceral resection $(* p<0.001)$. d T stage $\geq 3(* p$ $=0.021)$ (statistical significance $(p<0.050)$ is indicated with an asterisk)

Surgical details are summarized in Table 1.

\section{Histopathological results}

Advanced local tumor growth (defined as $\mathrm{T}$ stage $\geq 3$ ) was observed in 59 (21.9\%) patients and significantly influenced patient survival (22.83 versus 29.50 months; $p=0.021$; Fig. 1d). Tumor multifocality (observed in 98 (36.4\%) patients) was associated with higher RSI values (mean: 1.89 versus 1.57; median: 1.20 versus $0.86 ; p=0.001)$.

Lymphadenectomy was performed in 172 (63.9\%) patients, verifying regional lymph node metastases (N1) in 76 (28.3\%) patients. Both variables (lymphadenectomy and positive nodal status) were associated with significantly inferior survival (25.23 versus 38.11 months; $p=0.007$ and 14.36 versus 32.63 months; $p<0.001$, respectively). Of note, we observed a non-significant trend towards increased rates of lymphadenectomy during the analyzed time period (1996-2003: 60.0\%, 2004-2011: 63.5\%, 2012-2018: 68.2\%; $p=0.541)$.

Distant metastases were observed in 7 (2.6\%) patients with peritoneal metastases being observed most frequently (four patients) followed by metastases in the greater omentum, the kidney, and the mediastinal lymph nodes (one patient each). Distant metastases were associated with significantly inferior survival (4.96 versus 28.03 months; $p<0.001$ ). 
Positive resection margins (R1) were observed in 37 $(13.8 \%)$ patients. Further analyses did not reveal significant influence of R1 status on postoperative median survival (20.93 versus 29.50 months; $p=0.376$ ).

Due to the low rate of lymphadenectomy and missing information on vascular invasion, distinct allocation into the AJCC/UICC stages was only possible for $174(64.7 \%)$ patients. Advanced AJCC/UICC stages of $\geq$ IIIa were observed in $118(43.9 \%)$ patients.

The rate of histological evidence for cholestasis (37 (13.8\%) patients) or cholangitis (17 (6.3\%) patients) was not significantly increased in patients with preoperative leukocytosis $(20.5 \%$ versus $12.7 \%, p=0.144$ and $12.8 \%$ versus $5.2 \%$, $p=0.082$, respectively).

The histopathological results are summarized in Table 1.

\section{Postoperative course and outcome}

Severe postoperative complications after hepatic resection were observed in 94 (34.9\%) patients. Eighteen (6.7\%) patients died in the postoperative course, mainly due to posthepatectomy liver failure (seven patients). Further lethal complications were biliary leakage (four patients), cardiac failure (two patients), pneumonia (two patients), severe bleeding, portal vein thrombosis, and mesenteric ischemia (one patient each) ultimately leading to multiple organ failure.

Patients were followed up after hepatic resection with a median of 22.93 (0.10-234.39) months.

Estimated median postoperative survival was 27.63 months. The 1-, 3-, and 5-year survival rates were $71.9 \%$, $41.5 \%$, and $27.4 \%$, respectively.

Of note, the postoperative survival did not significantly alter over the course of time (1996-2003 (80 patients): 26.32 months, 2004-2011 (104 patients): 27.93 months, 2012-2018 (85 patients): 26.78 months; $p=0.776$ ).

Table 2 summarizes the postoperative course and outcome after hepatic resection.

\section{Identification of independent risk factors for postoperative morbidity and mortality}

The results from univariable analysis evaluating risk factors for the incidence of severe postoperative complications are displayed in Table 3.

Multivariable analysis identified the body mass index (OR: 1.072; CI-95\%: $1.005-1.143 ; p=0.035)$, the RSI (OR: 1.335; CI-95\%: $1.084-1.643 ; p=0.006)$, hilar bile duct resection (OR: 2.825; CI-95\%: $1.358-5.876 ; p=0.005$ ), and number of PRBC transfused intraoperatively (OR: 1.116; CI-95\%: $1.007-1.237 ; p=0.036$ ) as independent significant risk factors for severe postoperative complications (Table 3).

The results from univariable analysis evaluating risk factors for postoperative survival are displayed in Table 4 .
Multivariable analysis identified preoperative leukocytosis (HR: 1.857 ; CI-95\%: $1.232-2.799 ; p=0.003$ ), the RSI (HR: 1.081; CI-95\%: $1.024-1.141 ; p=0.005)$, multivisceral resection (HR: 3.665; CI-95\%: 1.751-7.671; $p=0.001$ ), and T stage $\geq 3$ (HR: 1.532; CI-95\%: $1.094-2.146 ; p=0.013$ ) as independent significant risk factors for postoperative survival (Table 4).

\section{Discussion}

The prognosis of patients with ICC remains unsatisfying, despite efforts of improving surgical and non-surgical treatment in the past. Although the importance of surgical resection to achieve long-term survival is undisputed, not all patients benefit from hepatic resections. Especially in cases of advanced disease, poor survival rates were reported in previous publications of larger mono- and multicentric studies as confirmed in our present work $[10,14,20]$. With respect to the simultaneously reported considerable postoperative mortality of up to $10 \%$, preoperative risk stratification is imperatively indicated [21].

Several studies have emphasized the prognostic value of inflammatory parameters and indices, such as elevated serum C-reactive protein levels or elevated neutrophil to lymphocyte ratios on postoperative survival in patients undergoing surgery for ICC [22-27]. To our knowledge, our study is the first to identify preoperative leukocytosis as an independent risk factor for survival. Although patients with high leukocyte concentrations did not show significantly elevated serum bilirubin concentration as a sign of obstructive cholestasis, concomitant elevation of serum gamma-glutamyltransferase and alkaline phosphatase, as well as C-reactive protein levels, was detected in most patients with preoperative leukocytosis prompting the assumption of underlying cholangitis as reason for our observations. However, only four patients exhibited typical clinical symptoms, such as fever, rigor, or jaundice and postoperative histological analysis did not reveal a statistically significant association between preoperative leukocytosis and the evidence of cholestasis or cholangitis. Furthermore, we did not observe an increase of severe or septic postoperative complications in the respective subgroup, and increased mortality was not limited to the immediate postoperative course but was observed throughout the entire follow-up. Of note, asymptomatic preoperative leukocytosis has been identified as a risk factor for an increase in morbidity and mortality in patients undergoing surgery for colorectal carcinoma. The authors state that apart from an inflammatory environment depending on the respective tumor immunogenicity, most commonly discussed as explanation for the findings, preoperative dehydration and malnutrition leading to leukocytosis could also be a reason for an inferior postoperative outcome [28]. In summary, the association between preoperative 
Table 2 Postoperative outcome of the study cohort after resection of intrahepatic cholangiocarcinoma

\begin{tabular}{|c|c|c|c|c|}
\hline \multicolumn{2}{|l|}{ Variables } & \multirow{2}{*}{$\frac{n_{\mathrm{abs}}\left(n_{\%}\right)}{71(26.4)}$} & \multirow{2}{*}{$\begin{array}{l}\text { Mean; median (range) } \\
1.38 ; 0(0-29)\end{array}$} & \multirow{2}{*}{$\frac{\text { Missing values } n(\%)}{10(3.7)}$} \\
\hline $\begin{array}{l}\text { Postoperative PRBC } \\
\text { Postoperative PRBC }(n)\end{array}$ & & & & \\
\hline $\begin{array}{l}\text { Intensive care unit stay (in days) } \\
\text { Hospital stay (in days) }\end{array}$ & & & $\begin{array}{l}4.36 ; 2(0-91) \\
23.18 ; 20(4-95)\end{array}$ & $0(0)$ \\
\hline $\begin{array}{l}\text { Postoperative complications } \\
\quad \text { (classified by Clavien-Dindo) }\end{array}$ & $\begin{array}{l}0 \\
\text { I } \\
\text { II } \\
\text { IIIa } \\
\text { IIIb } \\
\text { IVa } \\
\text { V } \\
\text { Severe complications }(\geq \text { IIIa) }\end{array}$ & $\begin{array}{l}59(21.9) \\
37(13.8) \\
77(28.6) \\
34(12.6) \\
37(13.8) \\
5(1.9) \\
18(6.7) \\
94(34.9)\end{array}$ & & $2(0.7)$ \\
\hline $\begin{array}{l}\text { Postoperative liver-specific } \\
\text { complications Grade C } \\
\text { (classified by ISGLS) }\end{array}$ & $\begin{array}{l}\text { Hemorrhage } \\
\text { Liver failure } \\
\text { Biliary leakage }\end{array}$ & $\begin{array}{l}8(3.0) \\
13(4.8) \\
13(4.8)\end{array}$ & & $2(0.7)$ \\
\hline $\begin{array}{l}\text { 30-day mortality } \\
\text { 90-day mortality }\end{array}$ & & $\begin{array}{l}11(4.1) \\
21(7.8)\end{array}$ & & $\begin{array}{l}4(1.5) \\
5(1.9)\end{array}$ \\
\hline $\begin{array}{l}\text { Follow-up time in months } \\
\text { Survival in months (Kaplan-Meier) }\end{array}$ & & & $\begin{array}{l}38.75 ; 22.93 \text { (0.10-234.39) } \\
52.61 ; 27.63 \text { (n.a.) }\end{array}$ & $4(1.5)$ \\
\hline 1-year survival (Kaplan-Meier) & & n.a. (71.9) & & \\
\hline 3-year survival (Kaplan-Meier) & & n.a. (41.5) & & \\
\hline 5-year survival (Kaplan-Meier) & & n.a. (27.4) & & \\
\hline Deceased at time of analysis & & $207(77.0)$ & & \\
\hline
\end{tabular}

Postoperative outcome of the 269 patients undergoing surgery for intrahepatic cholangiocarcinoma

PRBC packed red blood cells, n.a. not applicable

leukocytosis and the observed increase in mortality in our patients remains unclear and needs further evaluation in prospective clinical trials.

Prognostic stratification scores for survival after resection of different malignancies, including ICC, have been published in recent years to optimize perioperative decision making [29-32]. We have recently introduced the RSI, estimating the future functional liver remnant with respect to the preoperative liver function and the expected or actual extent of hepatic surgery, as an independent risk factor for survival after resection of hepatocellular carcinoma and colorectal liver metastases $[11,12]$. In the current study, we were able to demonstrate the significance of the RSI as an independent risk factor for the onset of severe postoperative complications, as well as postoperative survival for patients undergoing resection of ICC. Interestingly, the RSI was not only a prognostic factor for early postoperative morbidity and mortality but also for long-term survival. This may be a result of an association between higher RSI values and tumor multifocality, which was identified as dependent risk factor for postoperative survival. Unlike other prominent scores, such as the recently validated MEGNA score, the RSI does not require postoperative data (e.g., histopathological staging) and thus can be of value not only for post- but also for preoperative therapeutic decision-making [14]. Of note, further well-known risk assessment scores, such as the FIB-4, ALBI, or Heidelberg score, were not further evaluated in the current study due to a lack of consistent preoperative monitoring of all required variables [33].

Due to the fact that the RSI focuses on the extent of hepatic resection, we also evaluated the influence of extrahepatic resections, such as additional hilar bile duct, vascular or multivisceral resections. Perhaps unsurprisingly, additional hilar bile duct resections significantly increased the incidence of severe postoperative complications, mainly as a result of insufficiency of the biliodigestive anastomosis and consecutive bile leakage. Extrahepatic or hilar bile duct resections are primarily associated with distal or perihilar cholangiocarcinoma. Thus, data on the rate and influence in patients with ICC is comparatively scarce. In a large meta-analysis on prognostic factors after resection of ICC, Mavros et al. reported a rate of extrahepatic bile duct resections (23\%) comparable with the data presented in our study (19\%). As observed in our uni- but not in multivariable analysis, some of the included studies demonstrated an association with inferior postoperative survival without commenting on the effects on postoperative 
Table 3 Logistic regression analysis for identification of risk factors for the incidence of severe postoperative complications after hepatic resection

\begin{tabular}{|c|c|c|c|c|c|c|c|}
\hline \multirow[t]{2}{*}{ Variables } & & \multicolumn{3}{|c|}{ Univariable analysis } & \multicolumn{3}{|c|}{ Multivariable analysis } \\
\hline & & OR & CI-95\% & $p$ value & OR & CI-95\% & $p$ value \\
\hline \multirow[t]{3}{*}{ Biometrics } & Male gender & 1.127 & $(0.682-1.863)$ & 0.640 & & & \\
\hline & Age (in years) & 0.991 & $(0.969-1.014)$ & 0.447 & & & \\
\hline & Body mass index $\left(\mathrm{kg} / \mathrm{m}^{2}\right)$ & 1.083 & $(1.022-1.148)$ & 0.007 & 1.072 & $(1.005-1.143)$ & 0.035 \\
\hline \multirow{10}{*}{$\begin{array}{l}\text { Preoperative laboratory } \\
\text { results }\end{array}$} & Hemoglobin (in g/dl) & 0.945 & $(0.817-1.092)$ & 0.441 & & & \\
\hline & Anemia & 1.211 & $(0.701-2.092)$ & 0.493 & & & \\
\hline & Leucocytes (in $10^{3} / \mu \mathrm{l}$ ) & 1.031 & $(0.952-1.116)$ & 0.456 & & & \\
\hline & Leukocytosis & 1.703 & $(0.857-3.386)$ & 0.129 & & & \\
\hline & Platelets (in $10^{3} / \mu \mathrm{l}$ ) & 1.000 & $(0.998-1.002)$ & 0.911 & & & \\
\hline & Quick (in \%) & 0.982 & $(0.966-0.999)$ & 0.041 & & & \\
\hline & ASAT (in U/l) & 1.011 & $(1.003-1.019)$ & 0.008 & & & \\
\hline & ALAT (in U/l) & 1.005 & $(1.000-1.011)$ & 0.071 & & & \\
\hline & Bilirubin (in $\mu \mathrm{mol} / \mathrm{l}$ ) & 1.007 & $(1.000-1.014)$ & 0.036 & & & \\
\hline & Creatinine (in $\mu \mathrm{mol} / \mathrm{l}$ ) & 1.000 & $(0.986-1.015)$ & 0.958 & & & \\
\hline \multirow[t]{18}{*}{ Surgical details } & Major hepatectomy & 3.498 & $(1.495-8.185)$ & 0.004 & & & \\
\hline & Extended hepatectomy & 1.418 & $(0.842-2.386)$ & 0.189 & & & \\
\hline & Resection points (continuous) & 1.260 & $(1.067-1.490)$ & 0.007 & & & \\
\hline & Resection points 1 & 0.229 & $(0.051-1.024)$ & 0.054 & & & \\
\hline & Resection points 2 & 0.500 & $(0.207-1.207)$ & 0.123 & & & \\
\hline & Resection points 3 & 0.758 & $(0.437-1.316)$ & 0.325 & & & \\
\hline & Resection points 4 & 2.201 & $(1.123-4.313)$ & 0.022 & & & \\
\hline & Resection points 5 & 1.014 & $(0.463-2.218)$ & 0.973 & & & \\
\hline & Resection points 6 & 1.534 & $(0.860-2.734)$ & 0.147 & & & \\
\hline & RSI & 1.409 & $(1.157-1.717)$ & 0.001 & 1.335 & $(1.084-1.643)$ & 0.006 \\
\hline & Hilar bile duct resection & 3.393 & $(1.808-6.367)$ & $<0.001$ & 2.825 & $(1.358-5.876)$ & 0.005 \\
\hline & Vascular resection & 2.881 & $(0.792-10.477)$ & 0.108 & & & \\
\hline & Multivisceral resection & 1.564 & $(0.464-5.267)$ & 0.471 & & & \\
\hline & Operation time (in min) & 1.005 & $(1.002-1.008)$ & 0.001 & & & \\
\hline & Pringle maneuver & 0.909 & $(0.433-1.912)$ & 0.802 & & & \\
\hline & Pringle maneuver (in min) & 1.006 & $(0.990-1.023)$ & 0.436 & & & \\
\hline & Intraoperative PRBC & 1.681 & $(1.007-2.805)$ & 0.047 & & & \\
\hline & Intraoperative PRBC (n) & 1.156 & $(1.054-1.267)$ & 0.002 & 1.116 & $(1.007-1.237)$ & 0.036 \\
\hline \multirow{17}{*}{$\begin{array}{l}\text { Postoperative } \\
\text { pathological results }\end{array}$} & Tumor size (in cm) & 1.028 & $(0.964-1.097)$ & 0.396 & & & \\
\hline & Vascular invasion & 1.861 & $(0.963-3.597)$ & 0.065 & & & \\
\hline & Multifocal & 1.616 & $(0.963-2.711)$ & 0.069 & & & \\
\hline & T stage $\geq 3$ & 2.200 & $(1.217-3.978)$ & 0.009 & & & \\
\hline & Lymphadenectomy & 1.110 & $(0.655-1.880)$ & 0.699 & & & \\
\hline & Lymph nodes ( $n$ total) & 1.056 & $(0.986-1.131)$ & 0.122 & & & \\
\hline & Lymph nodes ( $n$ positive) & 1.138 & $(0.974-1.329)$ & 0.104 & & & \\
\hline & N 1 stage & 1.143 & $(0.613-2.132)$ & 0.674 & & & \\
\hline & M 1 stage & 0.299 & $(0.035-2.524)$ & 0.267 & & & \\
\hline & Grading $>2$ & 1.537 & $(0.887-2.665)$ & 0.126 & & & \\
\hline & Positive resection margin (R1) & 1.234 & $(0.600-2.538)$ & 0.568 & & & \\
\hline & AJCC/UICC8 $\geq$ IIIa & 1.555 & $(0.845-2.859)$ & 0.156 & & & \\
\hline & Steatosis & 1.273 & $(0.748-2.166)$ & 0.374 & & & \\
\hline & Fibrosis & 1.166 & $(0.656-2.076)$ & 0.600 & & & \\
\hline & Cirrhosis & 1.564 & $(0.464-5.267)$ & 0.471 & & & \\
\hline & Cholestasis & 0.996 & $(0.482-2.062)$ & 0.992 & & & \\
\hline & Cholangitis & 1.695 & $(0.631-4.550)$ & 0.295 & & & \\
\hline
\end{tabular}

Results of the binary logistic regression analysis for identification of risk factors for the incidence of severe postoperative complications after resection of intrahepatic cholangiocarcinoma. Bold values indicate statistical significance $(p<0.050)$ in univariable or multivariable analysis

$O R$ odds ratio, $C I$ confidence interval, $A S A T$ aspartate aminotransferase, $A L A T$ alanine aminotransferase, $R S I$ resection severity index, $P R B C$ Packed red blood cells, AJCC American Joint Committee on Cancer, UICC Union for International Cancer Control 
Table 4 Cox regression analysis for identification of risk factors for survival after hepatic resection of intrahepatic cholangiocarcinoma

\begin{tabular}{|c|c|c|c|c|c|c|c|}
\hline \multirow[t]{2}{*}{ Variables } & & \multicolumn{3}{|c|}{ Univariable analysis } & \multicolumn{3}{|c|}{ Multivariable analysis } \\
\hline & & HR & CI-95\% & $p$ value & HR & CI-95\% & $p$ value \\
\hline \multirow[t]{3}{*}{ Biometrics } & Male gender & 0.962 & $(0.732-1.264)$ & 0.783 & & & \\
\hline & Age (in years) & 0.997 & $(0.985-1.011)$ & 0.703 & & & \\
\hline & Body mass index $\left(\mathrm{kg} / \mathrm{m}^{2}\right)$ & 1.019 & $(0.988-1.050)$ & 0.237 & & & \\
\hline \multirow[t]{10}{*}{ Preoperative laboratory results } & Hemoglobin (in $\mathrm{g} / \mathrm{dl}$ ) & 0.915 & $(0.844-0.992)$ & 0.032 & & & \\
\hline & Anemia & 1.341 & $(0.997-1.803)$ & 0.053 & & & \\
\hline & Leukocytes (in $10^{3} / \mu \mathrm{l}$ ) & 1.088 & $(1.044-1.133)$ & $<0.001$ & & & \\
\hline & Leukocytosis & 1.907 & $(1.313-2.771)$ & 0.001 & 1.857 & $(1.232-2.799)$ & 0.003 \\
\hline & Platelets (in $10^{3} / \mu \mathrm{l}$ ) & 1.001 & $(1.000-1.002)$ & 0.061 & & & \\
\hline & Quick (in \%) & 0.984 & $(0.974-0.994)$ & 0.003 & & & \\
\hline & ASAT (in U/l) & 1.005 & $(1.001-1.009)$ & 0.024 & & & \\
\hline & ALAT (in U/l) & 1.002 & $(0.999-1.005)$ & 0.290 & & & \\
\hline & Bilirubin (in $\mu \mathrm{mol} / \mathrm{l}$ ) & 1.004 & $(1.002-1.007)$ & 0.002 & & & \\
\hline & Creatinine (in $\mu \mathrm{mol} / \mathrm{l}$ ) & 1.003 & $(0.995-1.011)$ & 0.514 & & & \\
\hline \multirow[t]{18}{*}{ Surgical details } & Major hepatectomy & 1.253 & $(0.846-1.857)$ & 0.261 & & & \\
\hline & Extended hepatectomy & 1.146 & $(0.865-1.520)$ & 0.342 & & & \\
\hline & Resection points (continuous) & 1.062 & $(0.972-1.159)$ & 0.182 & & & \\
\hline & Resection points 1 & 0.705 & $(0.373-1.332)$ & 0.281 & & & \\
\hline & Resection points 2 & 0.956 & $(0.608-1.503)$ & 0.845 & & & \\
\hline & Resection points 3 & 0.847 & $(0.631-1.137)$ & 0.270 & & & \\
\hline & Resection points 4 & 1.259 & $(0.865-1.832)$ & 0.229 & & & \\
\hline & Resection points 5 & 1.219 & $(0.807-1.843)$ & 0.346 & & & \\
\hline & Resection points 6 & 1.063 & $(0.776-1.457)$ & 0.703 & & & \\
\hline & RSI & 1.104 & $(1.051-1.161)$ & $<0.001$ & 1.081 & $(1.024-1.141)$ & 0.005 \\
\hline & Hilar bile duct resection & 1.534 & $(1.096-2.146)$ & 0.013 & & & \\
\hline & Vascular resection & 2.105 & $(1.072-4.133)$ & 0.031 & & & \\
\hline & Multivisceral resection & 4.387 & $(2.280-8.440)$ & $<0.001$ & 3.665 & $(1.751-7.671)$ & 0.001 \\
\hline & Operation time (in min) & 1.002 & $(1.001-1.004)$ & $<0.001$ & & & \\
\hline & Pringle maneuver & 0.815 & $(0.554-1.199)$ & 0.300 & & & \\
\hline & Pringle maneuver (in min) & 1.002 & $(0.992-1.011)$ & 0.703 & & & \\
\hline & Intraoperative PRBC & 1.427 & $(1.082-1.883)$ & 0.012 & & & \\
\hline & Intraoperative PRBC $(n)$ & 1.086 & $(1.037-1.137)$ & $<0.001$ & & & \\
\hline \multirow[t]{17}{*}{ Postoperative pathological results } & Tumor size (in cm) & 1.024 & $(0.990-1.059)$ & 0.169 & & & \\
\hline & Vascular invasion & 2.201 & $(1.505-3.221)$ & $<0.001$ & & & \\
\hline & Multifocal & 1.497 & $(1.128-1.986)$ & 0.005 & & & \\
\hline & T stage $\geq 3$ & 1.452 & $(1.056-1.996)$ & 0.022 & 1.532 & $(1.094-2.146)$ & 0.013 \\
\hline & Lymphadenectomy & 1.488 & $(1.113-1.991)$ & 0.007 & & & \\
\hline & Lymph nodes (n total) & 1.028 & $(0.994-1.063)$ & 0.103 & & & \\
\hline & Lymph nodes (n positive) & 1.105 & $(1.032-1.184)$ & 0.004 & & & \\
\hline & N 1 stage & 2.193 & $(1.544-3.116)$ & $<0.001$ & & & \\
\hline & M 1 stage & 4.384 & $(1.765-10.891)$ & 0.001 & & & \\
\hline & Grading $>2$ & 1.140 & $(0.848-1.533)$ & 0.384 & & & \\
\hline & Positive resection margin (R 1) & 1.192 & $(0.808-1.759)$ & 0.377 & & & \\
\hline & AJCC/UICC8 $\geq$ IIIa & 1.903 & $(1.355-2.673)$ & $<0.001$ & & & \\
\hline & Steatosis & 1.028 & $(0.763-1.386)$ & 0.854 & & & \\
\hline & Fibrosis & 1.008 & $(0.729-1.394)$ & 0.962 & & & \\
\hline & Cirrhosis & 1.282 & $(0.656-2.505)$ & 0.467 & & & \\
\hline & Cholestasis & 1.278 & $(0.861-1.897)$ & 0.223 & & & \\
\hline & Cholangitis & 1.220 & $(0.695-2.143)$ & 0.488 & & & \\
\hline
\end{tabular}

Results of the Cox regression analysis for identification of risk factors for survival after resection of intrahepatic cholangiocarcinoma. Bold values indicate statistical significance $(p<0.050)$ in univariable or multivariable analysis

$H R$ hazard ratio, $C I$ confidence interval, $A S A T$ aspartate aminotransferase, $A L A T$ alanine aminotransferase, $R S I$ resection severity index, $P R B C$ packed red blood cells, AJCC American Joint Committee on Cancer, UICC Union for International Cancer Control 
morbidity [20]. Although definitions of (multi-)visceral resections are vague throughout the literature, sometimes including resections of major vessels or extrahepatic bile ducts, previous publications have emphasized that resection of adjacent organs results in inferior overall survival [10, 34]. In our study, multivisceral resection - defined as resection of extrahepatic tissue excluding extrahepatic bile ducts and major vesselswas identified as major predictor of inferior survival (with a median survival of only 4.96 months) in multivariable analysis. We therefore suggest critical evaluation of operability in case of pre- or intraoperatively suspected invasion of adjacent organs.

Lastly, histopathological factors, including positive resection margins, were evaluated as prognostic factors. A vast majority of available literature, including meta-analyses, states the importance of tumor-free resection margins to achieve long-term survival $[10,21,35]$. Surprisingly, positive resection margins did not have significant influence on postoperative survival, neither in uni- nor multivariable analysis. Of note, the width of the surgical margins was not analyzed in the present study since its relevance is generally discussed controversial: some recent publications pointed out that wide surgical margins (mostly defined as $\geq 10 \mathrm{~mm}$ ) ensure better overall survival, whereas others reported conflicting results, especially with regard to lymph node-positive patients [36, 37]. Other known histopathological factors including high AJCC/UICC stages were confirmed as risk factors in univariable analysis, but only an advanced $\mathrm{T}$ stage was identified as an independent risk factor for survival in multivariable analysis in this study. As stated above, this is a result of the high rate of missing values regarding lymph node dissection and staging and consequentially AJCC/UICC classification, leading to an exclusion of the respective variables from multivariable analysis.

Although the role of lymph node metastases as a poor prognostic factor with concomitant high disease recurrence rates is undisputed, the benefit of simultaneous lymphadenectomy in patients with ICC has been a matter of great debate since the latest AJCC/UICC edition recommended harvesting at least six lymph nodes along the portal vein for proper staging [38-42]. In our patient series, we observed a slight increase of lymphadenectomies over the last three decades resulting in an overall lymph node dissection rate of $63 \%$. Lymphadenectomy was associated with inferior survival in our patients as opposed to other studies in the past [43]. A systematic review and meta-analysis by Zhou et al. concluded that lymphadenectomy does not improve disease-free or overall survival but instead increases postoperative morbidity. Furthermore, in the case of lymph node positivity, lymph node dissection results in worse survival [44]. Kizy et al. even showed that surgical resection of lymph node positive ICC does not improve survival when compared with chemotherapy alone [45]. Others, however, have demonstrated better survival after lymph node dissection in case of lymph node negativity [46]. In summary, the positive effect of lymph node dissections for patient survival after resection of ICC remains highly questionable. However, keeping in mind innovations in medical treatment for cholangiocarcinoma, identification of lymph node-positive patients via lymph node dissection could prove crucial in determining further adjuvant therapeutic strategies in the future [47].

Major limitations of our study are missing information on disease recurrence and adjuvant therapy. Especially the latter seems important since recent meta-analyses by Rangarajan and Ma et al. have demonstrated the efficacy of postoperative adjuvant chemotherapy or radiochemotherapy for patients with positive resection margins, as well as lymph node infiltration after resection of biliary tract malignancies, and current guidelines on the matter clearly recommend adjuvant therapy upon resection [48-50]. However, Messina et al. reported opposing results in their meta-analysis and highlighted the increase of adverse events in patients undergoing adjuvant therapy after surgery [51]. Furthermore, our observations regarding the RSI are limited by the retrospective and monocentric nature of our study.

\section{Conclusion}

Preoperative leukocytosis and the RSI are useful variables for preoperative risk stratification since they were identified as significant predictors for postoperative morbidity and mortality, respectively. Prospective clinical trials are now required to validate our findings.

Authors' contributions Study conception and design: Oliver Beetz, Moritz Kleine, and Felix Oldhafer. Acquisition of data: Oliver Beetz, Clara A. Weigle, Hüseyin Bektas, and Felix Oldhafer. Analysis and interpretation of data: Oliver Beetz, Clara A. Weigle, Moritz Kleine, and Felix Oldhafer. Drafting of manuscript: Oliver Beetz, Sebastian Cammann, Moritz Kleine, and Felix Oldhafer. Critical revision of manuscript: Florian W. R. Vondran, Ulf Kulik, Kai Timrott, and Jürgen Klempnauer

Funding Information Open Access funding provided by Projekt DEAL.

Data availability The datasets used and/or analyzed during the current study are available from the corresponding author on reasonable request.

\section{Compliance with ethical standards}

Conflicts of interest The authors declare that they have no competing interests.

Ethics approval Patients provided informed consent that their data may be used for scientific purposes at the time of hospital admission, which is the general policy of our institution. The ethical committee of the Hannover Medical School stated that no further approval for retrospective 
analyses is needed. Patient records and patient data were anonymized and de-identified prior to analysis.

Code availability Not applicable.

Consent to participate See above.

Consent for publication Not applicable.

Open Access This article is licensed under a Creative Commons Attribution 4.0 International License, which permits use, sharing, adaptation, distribution and reproduction in any medium or format, as long as you give appropriate credit to the original author(s) and the source, provide a link to the Creative Commons licence, and indicate if changes were made. The images or other third party material in this article are included in the article's Creative Commons licence, unless indicated otherwise in a credit line to the material. If material is not included in the article's Creative Commons licence and your intended use is not permitted by statutory regulation or exceeds the permitted use, you will need to obtain permission directly from the copyright holder. To view a copy of this licence, visit http://creativecommons.org/licenses/by/4.0/.

\section{References}

1. Gupta A, Dixon E (2017) Epidemiology and risk factors: intrahepatic cholangiocarcinoma. HepatoBiliary Surg Nutr 6:101104. https://doi.org/10.21037/hbsn.2017.01.02

2. Walter D, Ferstl P, Waidmann O, Trojan J, Hartmann S, Schnitzbauer AA, Zeuzem S, Kraywinkel K (2019) Cholangiocarcinoma in Germany: epidemiologic trends and impact of misclassification. Liver Int 39:316-323. https://doi.org/10.1111/liv.13954

3. Kaneko R, Sato Y, Kobayashi Y (2018) Cholangiocarcinoma prognosis varies over time depending on tumor site and pathology. $\mathrm{J}$ Gastrointest Liver Dis 27:59-66. https://doi.org/10.15403/jgld. 2014.1121.271.kak

4. Koay EJ, Odisio BC, Javle M et al (2017) Management of unresectable intrahepatic cholangiocarcinoma: how do we decide among the various liver-directed treatments? HepatoBiliary Surg Nutr 6:105-116. https://doi.org/10.21037/hbsn.2017.01.16

5. Chun YS, Javle M (2017) Systemic and adjuvant therapies for intrahepatic cholangiocarcinoma. Cancer Control 24: 107327481772924

6. Currie BM, Soulen MC (2017) Decision making: intra-arterial therapies for cholangiocarcinoma-TACE and TARE. Semin Interv Radiol 34:92-100. https://doi.org/10.1055/s-0037-1602591

7. Lee DD, Croome KP, Musto KR, Melendez J, Tranesh G, Nakhleh R, Taner CB, Nguyen JH, Patel T, Harnois DM (2018) Liver transplantation for intrahepatic cholangiocarcinoma. Liver Transpl 24: 634-644. https://doi.org/10.1002/lt.25052

8. Yousaf A, Kim JU, Eliahoo J, Taylor-Robinson SD, Khan SA (2019) Ablative therapy for unresectable intrahepatic cholangiocarcinoma: a systematic review and meta-analysis. J Clin Exp Hepatol 9:740-748

9. Cucchetti A, Cappelli A, Mosconi C, Zhong JH, Cescon M, Pinna AD, Golfieri R (2017) Improving patient selection for selective internal radiation therapy of intra-hepatic cholangiocarcinoma: a meta-regression study. Liver Int 37:1056-1064. https://doi.org/10.1111/liv.13382

10. Waisberg DR, Pinheiro RS, Nacif LS, Rocha-Santos V, Martino RB, Arantes RM, Ducatti L, Lai Q, Andraus W, D'Albuquerque LC (2018) Resection for intrahepatic cholangiocellular cancer: new advances. Transl Gastroenterol Hepatol 3

11. Gwiasda J, Schulte A, Kaltenborn A et al (2017) Identification of the resection severity index as a significant independent prognostic factor for early mortality and observed survival $>5$ and $>10$ years after liver resection for hepatocellular carcinoma. Surg Oncol 26: 178-187

12. Gwiasda J, Schrem H, Kaltenborn A, Mahlmann J, Mix H, Lehner F, Kayser N, Klempnauer J, Kulik U (2017) Introduction of the resection severity index as independent risk factor limiting survival after resection of colorectal liver metastases. Surg Oncol 26:382388. https://doi.org/10.1016/j.suronc.2017.08.002

13. Shapiro MF, Greenfield S (1987) The complete blood count and leukocyte differential count. An approach to their rational application. Ann Intern Med 106:65-74

14. Schnitzbauer AA, Eberhard J, Bartsch F, Brunner SM, Ceyhan GO, Walter D, Fries H, Hannes S, Hecker A, Li J, Oldhafer K, Rahbari N, Rauchfuss F, Schlitt HJ, Settmacher U, Stavrou G, Weitz J, Lang H, Bechstein WO, Rückert F (2019) The MEGNA score and preoperative anemia are major prognostic factors after resection in the German intrahepatic cholangiocarcinoma cohort. Ann Surg Oncol 27:1147-1155. https://doi.org/10.1245/s10434-019-07968-7

15. Strasberg SM (2005) Nomenclature of hepatic anatomy and resections: a review of the Brisbane 2000 system. J Hepato-BiliaryPancreat Surg 12:351-355. https://doi.org/10.1007/s00534-0050999-7

16. Dindo D, Demartines N, Clavien PA (2004) Classification of surgical complications: a new proposal with evaluation in a cohort of 6336 patients and results of a survey. Ann Surg 240:205-213

17. Birgin E, Tesfazgi W, Knoth M, Wilhelm TJ, Post S, Rückert F (2019) Evaluation of the new ISGLS definitions of typical posthepatectomy complications. Scand J Surg 108:130-136. https://doi.org/10.1177/1457496918798202

18. Lee AJ, Chun YS (2018) Intrahepatic cholangiocarcinoma: the AJCC/UICC 8th edition updates. Chinese Clin Oncol 7

19. Kleiner DE, Brunt EM, Van Natta M et al (2005) Design and validation of a histological scoring system for nonalcoholic fatty liver disease. Hepatology 41:1313-1321. https://doi.org/10.1002/hep.20701

20. Mavros MN, Economopoulos KP, Alexiou VG, Pawlik TM (2014) Treatment and prognosis for patients with intrahepatic cholangiocarcinoma: systematic review and meta-analysis. JAMA Surg 149: 565-574. https://doi.org/10.1001/jamasurg.2013.5137

21. Cillo U, Fondevila C, Donadon M, Gringeri E, Mocchegiani F, Schlitt HJ, Ijzermans JNM, Vivarelli M, Zieniewicz K, Olde Damink SWM, Groot Koerkamp B (2019) Surgery for cholangiocarcinoma. Liver Int 39:143-155

22. Lin J, Fang T, Zhu M, Xu X, Zhang J, Zheng S, Jing C, Zhang M, Liu B, Zhang B (2019) Comparative performance of inflammationbased prognostic scores in patients operated for intrahepatic cholangiocarcinoma. Cancer Manag Res 11:9107-9119. https://doi.org/ 10.2147/CMAR.S198959

23. Wu Y, Ren F, Chai Y, Xue Z, Shen C, Zhang X, Lv Y, Hu L (2019) Prognostic value of inflammation-based indexes for intrahepatic cholangiocarcinoma following curative resection. Oncol Lett 17: 165-174. https://doi.org/10.3892/ol.2018.9618

24. Shinke G, Yamada D, Eguchi H, Iwagami Y, Akita H, Asaoka T, Noda T, Gotoh K, Kobayashi S, Takeda Y, Tanemura M, Doki Y, Mori M (2019) The postoperative peak number of leukocytes after hepatectomy is a significant prognostic factor for cholangiocarcinoma. Mol Clin Oncol 10:531. https://doi.org/10.3892/mco.2019.1827

25. Zhang Y, Shi SM, Yang H, Yang LX, Wang Z, Li XD, Yin D, Shi YH, Cao Y, Dai Z, Zhou J, Chen Q (2019) Systemic inflammation score predicts survival in patients with intrahepatic cholangiocarcinoma undergoing curative resection. J Cancer 10:494-503. https:// doi.org/10.7150/jca. 26890

26. Zheng BH, Yang LX, Sun QM, Fan HK, Duan M, Shi JY, Wang XY, Zhou J, Fan J, Ma ZY, Gao Q (2017) A new preoperative prognostic system combining CRP and CA199 for patients with intrahepatic cholangiocarcinoma. Clin Transl Gastroenterol 8: e118. https://doi.org/10.1038/ctg.2017.45 
27. Lin ZY, Liang ZX, Zhuang PL, Chen JW, Cao Y, Yan LX, Yun JP, Xie D, Cai MY (2016) Intrahepatic cholangiocarcinoma prognostic determination using pre-operative serum C-reactive protein levels. BMC Cancer 16:792. https://doi.org/10.1186/s12885-016-2827-7

28. Moghadamyeghaneh Z, Hanna MH, Carmichael JC, Mills SD, Pigazzi A, Stamos MJ (2015) Preoperative leukocytosis in colorectal cancer patients. J Am Coll Surg 221:207-214. https://doi.org/10. 1016/j.jamcollsurg.2015.03.044

29. Tsilimigras DI, Mehta R, Aldrighetti L, Poultsides GA, Maithel SK, Martel G, Shen F, Koerkamp BG, Endo I, Pawlik TM, Paredes AZ, Moris D, Sahara K, Bagante F, Guglielmi A, Weiss M, Bauer TW, Alexandrescu S, Marques HP, Pulitano C, Soubrane O, Cloyd JM, Ejaz A (2020) Development and validation of a laboratory risk score (LabScore) to predict outcomes after resection for intrahepatic cholangiocarcinoma. J Am Coll Surg 230:381-391.e2. https://doi. org/10.1016/j.jamcollsurg.2019.12.025

30. Sahara K, Tsilimigras DI, Mehta R, Bagante F, Guglielmi A, Aldrighetti L, Alexandrescu S, Marques HP, Shen F, Koerkamp BG, Endo I, Pawlik TM (2019) A novel online prognostic tool to predict long-term survival after liver resection for intrahepatic cholangiocarcinoma: The "metro-ticket" paradigm. J Surg Oncol 120: 223-230. https://doi.org/10.1002/jso.25480

31. Brustia R, Langella S, Kawai T, Fonseca GM, Schielke A, Colli F, Resende V, Fleres F, Roulin D, Leyman P, Giacomoni A, Granger B, Fartoux L, de Carlis L, Demartines N, Sommacale D, Sanches MD, Patrono D, Detry O, Herman P, Okumura S, Ferrero A, Scatton O, Uemoto S, Perdigao F, Nolasco F, Laroche S, Romagnoli R, Famularo S (2019) Preoperative risk score for prediction of long-term outcomes after hepatectomy for intrahepatic cholangiocarcinoma: report of a collaborative, international-based, external validation study. Eur J Surg Oncol 46:560-571. https://doi. org/10.1016/j.ejso.2019.10.041

32. Tsilimigras DI, Mehta R, Moris D, Sahara K, Bagante F, Paredes AZ, Moro A, Guglielmi A, Aldrighetti L, Weiss M, Bauer TW, Alexandrescu S, Poultsides GA, Maithel SK, Marques HP, Martel G, Pulitano C, Shen F, Soubrane O, Koerkamp BG, Endo I, Pawlik TM (2019) A machine-based approach to preoperatively identify patients with the most and least benefit associated with resection for intrahepatic cholangiocarcinoma: an international multiinstitutional analysis of 1146 patients. Ann Surg Oncol 27:1110 1119. https://doi.org/10.1245/s10434-019-08067-3

33. Ghamarnejad O, Khajeh E, Rezaei N, Afshari K, Adelian A, Nikdad M, Hoffmann K, Mehrabi A (2020) Comparative analysis of the discriminatory performance of different well-known risk assessment scores for extended hepatectomy. Sci Rep 10:1-9. https:// doi.org/10.1038/s41598-020-57748-7

34. Bartsch F, Baumgart J, Hoppe-Lotichius M, Schmidtmann I, Heinrich S, Lang H (2018) Visceral infiltration of intrahepatic cholangiocarcinoma is most prognostic after curative resection - retrospective cohort study of 102 consecutive liver resections from a single center. Int J Surg 55:193-200. https://doi.org/10.1016/j. ijsu.2018.05.027

35. Li MX, Bi XY, Li ZY, Huang Z, Han Y, Zhao JJ, Zhao H, Cai JQ (2016) Impaction of surgical margin status on the survival outcome after surgical resection of intrahepatic cholangiocarcinoma: a systematic review and meta-analysis. J Surg Res 203:163-173. https:// doi.org/10.1016/j.jss.2016.02.012

36. Tang H, Lu W, Li B et al (2016) Influence of surgical margins on overall survival after resection of intrahepatic cholangiocarcinoma A meta-analysis. Medicine (United States) 95:e4621

37. Watanabe Y, Matsuyama Y, Izumi N, Kubo S, Kokudo N, Sakamoto M, Shiina S, Takayama T, Nakashima O, Kudo M (2020) Effect of surgical margin width after R0 resection for intrahepatic cholangiocarcinoma: a nationwide survey of the Liver Cancer Study Group of Japan. Surgery 167:793-802. https://doi.org/10.1016/j.surg.2019.12.009
38. Lee AJ, Chun YS (2018) Intrahepatic cholangiocarcinoma: the AJCC/UICC 8 th edition updates. Chin Clin Oncol 7:6. https:// doi.org/10.21037/cco.v0i0.20321

39. Zhang XF, Chakedis J, Bagante F, Chen Q, Beal EW, Lv Y, Weiss M, Popescu I, Marques HP, Aldrighetti L, Maithel SK, Pulitano C, Bauer TW, Shen F, Poultsides GA, Soubrane O, Martel G, Groot Koerkamp B, Guglielmi A, Itaru E, Pawlik TM (2018) Trends in use of lymphadenectomy in surgery with curative intent for intrahepatic cholangiocarcinoma. Br J Surg 105:857-866. https:// doi.org/10.1002/bjs.10827

40. Lendoire JC, Gil L, Imventarza O (2018) Intrahepatic cholangiocarcinoma surgery: the impact of lymphadenectomy. Chin Clin Oncol 7:53

41. Doussot A, Gonen M, Wiggers JK, et al Recurrence patterns and disease-free survival after resection of intrahepatic cholangiocarcinoma: preoperative and postoperative prognostic models. https:// doi.org/10.1016/j.jamcollsurg.2016.05.019

42. Zhang X-F, Xue F, Dong D-H, Weiss M, Popescu I, Marques HP, Aldrighetti L, Maithel SK, Pulitano C, Bauer TW, Shen F, Poultsides GA, Soubrane O, Martel G, Koerkamp BG, Itaru E, Lv Y, Pawlik TM (2020) Number and station of lymph node metastasis after curative-intent resection of intrahepatic cholangiocarcinoma impact prognosis. Ann Surg. https://doi.org/10.1097/SLA. 0000000000003788

43. Kim SH, Han DH, Choi GH, Choi JS, Kim KS (2019) Oncologic impact of lymph node dissection for intrahepatic cholangiocarcinoma: a propensity score-matched study. J Gastrointest Surg 23:538544. https://doi.org/10.1007/s11605-018-3899-2

44. Zhou R, Lu D, Li W, Tan W, Zhu S, Chen X, Min J, Shang C, Chen Y (2019) Is lymph node dissection necessary for resectable intrahepatic cholangiocarcinoma? A systematic review and metaanalysis. HPB 21:784-792

45. Kizy S, Altman AM, Marmor S, Wirth K, Ching Hui JY, Tuttle TM, Denbo JW, Jensen EH (2019) Surgical resection of lymph node positive intrahepatic cholangiocarcinoma may not improve survival. HPB 21:235-241. https://doi.org/10.1016/j.hpb.2018.08.006

46. Yoh T, Cauchy F, Le Roy B et al (2019) Prognostic value of lymphadenectomy for long-term outcomes in node-negative intrahepatic cholangiocarcinoma: a multicenter study. Surgery 166:975-982. https://doi.org/10.1016/j.surg.2019.06.025

47. Adeva J, Sangro B, Salati M, Edeline J, la Casta A, Bittoni A, Berardi R, Bruix J, Valle JW (2019) Medical treatment for cholangiocarcinoma. Liver Int 39:123-142

48. Rangarajan K, Simmons G, Manas D, Malik H, Hamady Z (2019) Systemic adjuvant chemotherapy for cholangiocarcinoma surgery: a systematic review and meta-analysis. Eur J Surg Oncol 45:2204

49. Ma KW, Cheung TT, Leung B, She BWH, Chok KSH, Chan ACY, Dai WC, Lo CM (2019) Adjuvant chemotherapy improves oncological outcomes of resectable intrahepatic cholangiocarcinoma: a meta-analysis. Medicine (Baltimore) 98:e14013. https://doi.org/10. 1097/MD.0000000000014013

50. Shroff RT, Kennedy EB, Bachini M, Bekaii-Saab T, Crane C, Edeline J, el-Khoueiry A, Feng M, Katz MHG, Primrose J, Soares HP, Valle J, Maithel SK (2019) Adjuvant therapy for resected biliary tract cancer: ASCO clinical practice guideline. J Clin Oncol 37:1015-1027. https://doi.org/10.1200/JCO.18.02178

51. Messina C, Merz V, Frisinghelli M, Trentin C, Grego E, Veccia A, Salati M, Messina M, Carnaghi C, Caffo O (2019) Adjuvant chemotherapy in resected bile duct cancer: a systematic review and meta-analysis of randomized trials. Crit Rev Oncol Hematol 143: $124-129$

Publisher's note Springer Nature remains neutral with regard to jurisdictional claims in published maps and institutional affiliations. 